\title{
Mechanical And Metallurgical Investigation Of Tig Welded-Brazed Aluminum And Stainless Steel Disimilar Joint By Using Copper Filler Rod
}

\author{
Sairam Kotari ${ }^{1,2}{ }^{*}$ Eshwaraiah Punna ${ }^{3}$ \\ ${ }^{I}$ Research Scholar, Gitam Demmed to be university, Hyderabad, India. \\ ${ }^{2}$ Assistant professor, Vardhaman College Of engineering, Hyderabad,India. \\ ${ }^{3}$ Professor, Gitam Demmed to be university, Hyderabad, India.
}

\begin{abstract}
Automobile bodies made by mix of steel and aluminum composites are getting famous in present days to decrease weight. Present work means to exhibit the strength of Aluminum and steel welded joint. Primary measures centered in this work are strength forecast, streamlining of welding measure boundaries and investigation of intermetallics. Base materials utilized are AA6061 aluminum alloys and SS304 hardened steel alloy. BCuP-4 copper filler bar is utilized for TIG welding/brazing of base metals. Taguchi L27 symmetrical exhibit with three elements is taken for plan of analyses. Analysis of Variance (ANOVA) a tool used to determine a remarkable effect of welding parameters and their performance significantly. In addition, experimental Tensile strength is compared to predicted values based on ANN. The results were found to be satisfactory. Formation Of IMCs were studied by doing SEM analysis.
\end{abstract}

Keywords: Brazing, AA6061, SS304, Mechanical Properties, Anova, FESEM

\section{Introduction}

Combination welding is an interaction which is truly challenging for $\mathrm{Al}$ and $\mathrm{Mg}$ amalgams for the explanation of the issues of hot break, porosity, and so on[1-5]. Additionally, varieties in the glass construction and liquefying point of the parent metals present difficulties for the binding by conventional combination welding methods of divergent joints (aluminum and magnesium compound). The intermetallic compounds are of miniature hardness somewhere in the range of 150 and $220 \mathrm{HV}$ relying upon the interface site, while the $\mathrm{Al}$ and $\mathrm{Mg}$ parent metals normal hardness of 25 to $60 \mathrm{HV}$. A perceptibly higher interface hardness contrasted with the $\mathrm{Al}$ and $\mathrm{Mg}$ parent metals demonstrates the development of high intermetallic hardness (IMCs) on the $\mathrm{Al} / \mathrm{Mg}$ interface, prompting a low combination welding power. The issues with Al/association Mg's of various composites are caused fundamentally by the formation of the fragile IMC layer in the dirt[5-10]. The key is to screen IMCs to eliminate or decrease the adverse consequence to work on joint force[10-13].

Honggang Dong [14] et all have done an examination on the joining of aluminum and steel blend with Aluminum-silicon-copper, Aluminum-Copper and Aluminum-Silicon filler rods and tracked down that a decent weld joint with incredible strength is procured with Al-Cu filler. J.L 
Song has done an examination of the intermetallic layer outlined by welding steel and aluminum with $\mathrm{Al}-\mathrm{Cu}$ filler and tracked down that these joint shows more break resistance. Huan He [15] et all has welded $\mathrm{Al}$ and $\mathrm{SS}$ with Nocolok change and $\mathrm{Ni}$ powder and exhibited a basic development in versatility. The advancement of thick IMC is a major issue in various welding of Steel and Alluminum compounds. IMCs are delicate in nature and get broken with little weights. The width of IMCs can be restricted by using coatings and transitions[16,17]. Transition upgrades the wetting and spreading of fluid filler metal. Presented here was an attempt to join Alluminum and steel with Copper filler rod. Further mechanical and microscopic characteristics were studied.

\section{Materials and Methods}

Base materials chose in this current task were AA6061 Aluminum compound plate and SS304 Stainless steel composite plate were $3 \mathrm{~mm}$ thick. Filler metals utilized were BCuP-4 copper filler bar of $2 \mathrm{~mm}$ in width. Metal organizations of base and filler metals were featured in table 1 and 2. Both Aluminum and Steel plates were cut into a size of $75 \times 75 \times 3 \mathrm{~mm}$. A solitary V furrow was made with an incline of $45^{\circ}$. Transition covering is applied on the examples[18,19]. Steel tests were preheated to a particular temperature to manage the qualifications in relaxing point to make a strong mix of melt metal, inciting the best quality joint. Since copper is a nice channel of warmth copper plate of $100 \mathrm{~mm}$ thick is used as a help plate at the base, examples were cut to the Copper plate[20,21]. In light of simplicity in welding and minimal expense gas tungsten welding (GTAW) is utilized. Welding boundarie are displayed in table 3. As indicated by ASTM standards, bendable test models were machined. ANOVA is utilized for further developing the data limits. Further the assessment of intermetallics were done.

Table 1:Metal composition of base metals

\begin{tabular}{|c|c|c|c|c|c|c|c|c|c|c|c|c|c|c|c|}
\hline Element & Al & $\mathrm{Si}$ & $\mathrm{C}$ & $\mathrm{Cu}$ & $\mathrm{Mn}$ & $\mathrm{Mg}$ & $\mathrm{Fe}$ & $\mathrm{Ni}$ & $\mathrm{Zn}$ & $\mathrm{Ti}$ & $\mathrm{Cr}$ & $\mathrm{Ph}$ & $\mathrm{Su}$ & $\mathrm{N}$ & Other \\
\hline $\begin{array}{c}\text { \% } \\
\text { of AA6061 }\end{array}$ & 97 & 0.7 & - & 0.3 & 0.1 & 0.9 & 0.6 & - & 0.2 & 0.1 & 0.3 & - & - & - & 0.1 \\
\hline $\begin{array}{c}\% \\
\text { Contribution } \\
\text { of SS304 }\end{array}$ & - & 1 & 0.1 & - & 2 & - & Rest & $\begin{array}{c}8.00 \\
10.50\end{array}$ & - & - & $\begin{array}{c}- \\
19.50\end{array}$ & 0 & 0 & 0.1 & - \\
\hline
\end{tabular}

Table 2: Metal Composition of Filler metals

\begin{tabular}{|c|c|c|c|c|c|c|c|}
\hline Element & $\mathrm{Ag}$ & $\mathrm{Cu}$ & $\mathrm{P}$ & $\mathrm{Ni}$ & $\mathrm{Fe}$ & $\mathrm{Mn}$ & $\mathrm{S}$ \\
\hline $\begin{array}{c}\% \\
\text { Contribution } \\
\text { of BCuP-4 }\end{array}$ & $\begin{array}{c}5.8- \\
6.2\end{array}$ & $\mathrm{Bal}$ & $\begin{array}{c}7.0- \\
7.5\end{array}$ & - & - & - & - \\
& & & & & & & \\
\hline
\end{tabular}


Table 3: Welding parameters

\begin{tabular}{|c|c|c|c|}
\hline Factor & Type & Levels & Values \\
\hline A & Fixed & 3 & $90-140$ \\
\hline B & Fixed & 3 & 100,120 \\
\hline C & Fixed & 3 & $8-10$ \\
\hline
\end{tabular}

Where A represents Weld current(Amp), B represents Weld speed(mm/min) and C represents Gas flow rate(L/min).

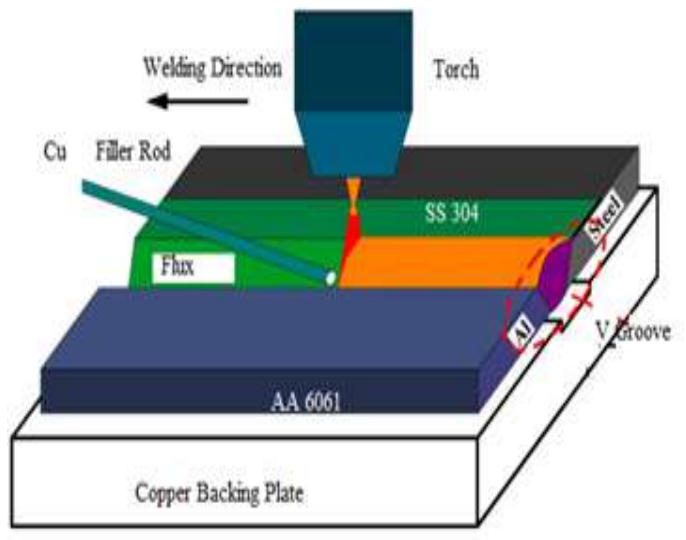

(a)

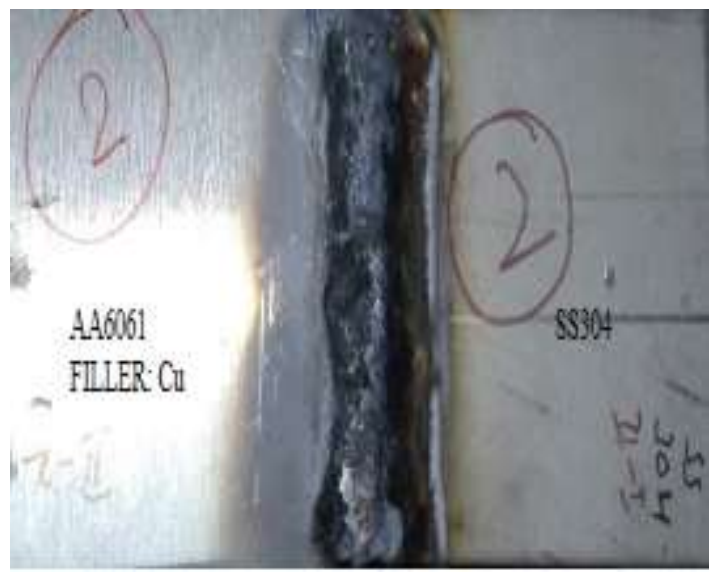

(b)

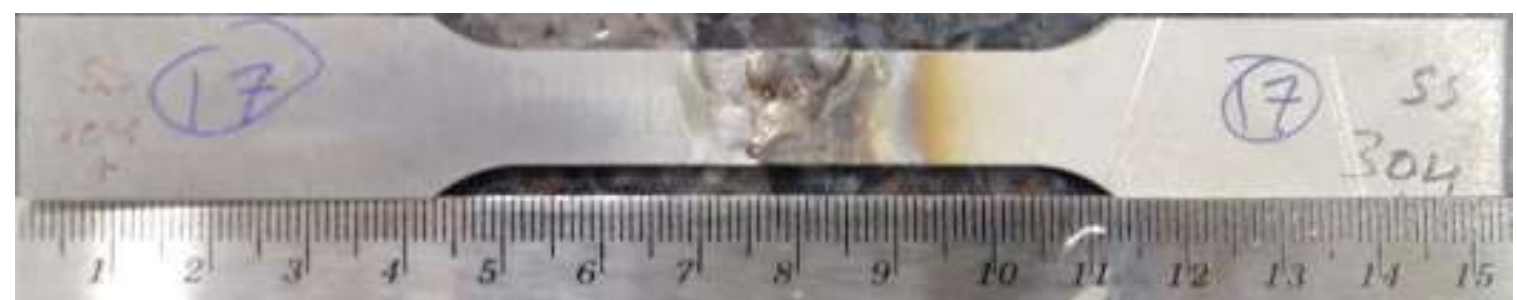

(c)

Fig 1: (a) line diagram,(b) Welded Sample (c) specimen prepared for tensile test

\section{Results and Discussion}

Tensile and shear testing are crucial for picking suitable materials during designing work. Sensible testing can in like way be utilized to confirm that materials adhere to the most unquality and prolongation necessities. Consequences of not adhering to raised presumptions can be remarkable both in real money related and human expenses. The utilization of inappropriate 
materials might accomplish the destruction of property and an essential death toll. The expenses of disturbances achieved by using inadmissible materials commonly far outflank the expenses of doing standard adaptable testing. After the arranging of weld as showed up in Fig 1 (c). Tests for the ductile test are machined on CNC wire EDM equipment as indicated by ASTM standard as showed up in Fig1 (c). The rigidity procured was showed up in figure 2. Shear Strength of the specimens were presented in Figure 3.

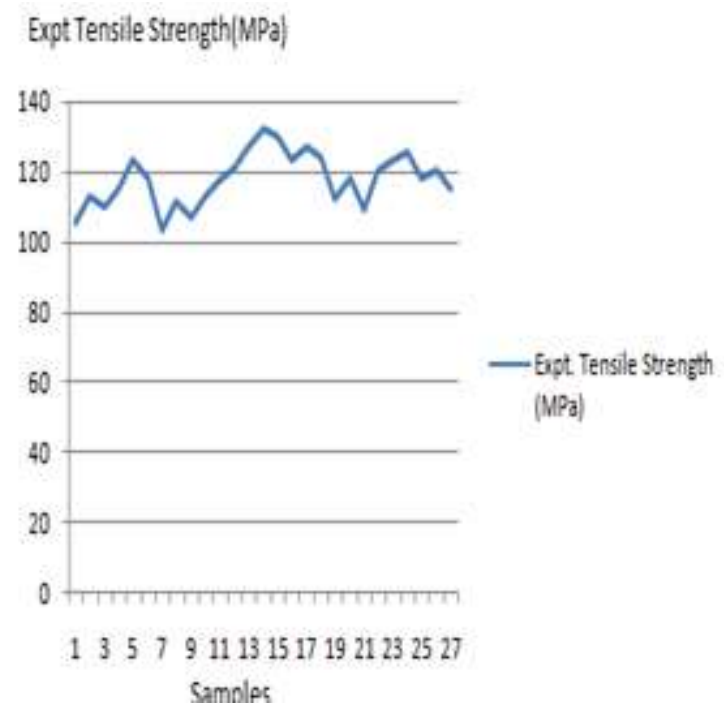

Fig 2: Tensile Strength Values

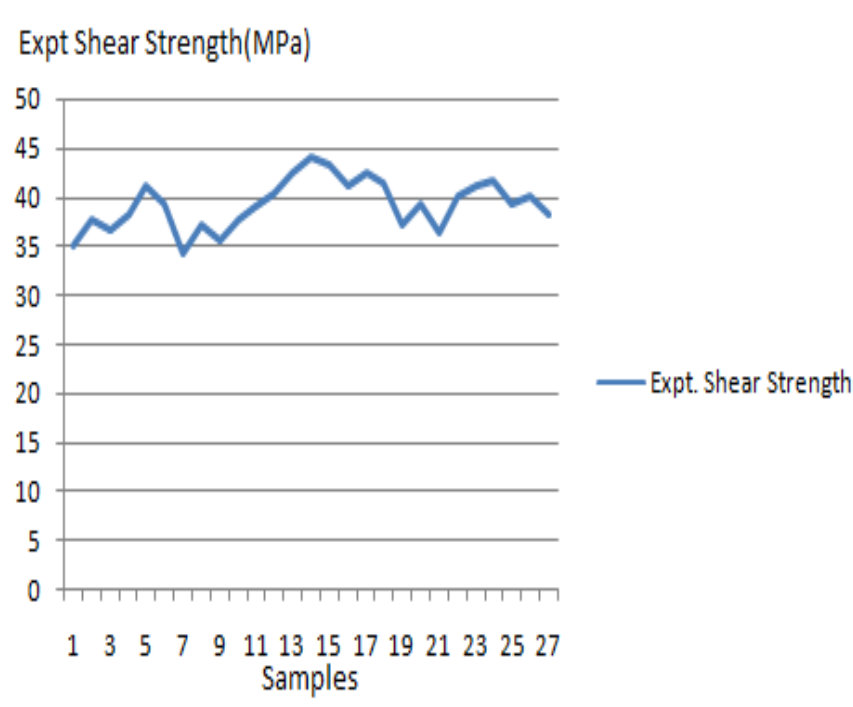

Fig 3: Shear Strength Values

Figure shows the shear break cycle of incorporated GTAW joint. The point among Al and steel sheets was right around zero in the underlying state as shown in Fig 4. The piece diversion point expanded to 3.94० when the heap arrived at its pinnacle. After the pinnacle load point, the breaks shaped at two focuses near the bolt in $\mathrm{Al}$ on the bolt measurement line, which is opposite to the ductile course and engendered outwards as shown in Fig 5. Crack happened at the joint in Steel Side for larger part of examples. This is because of reason that the HAZ is having high hardness thus it is fragile in nature. Break morphology showed delicate dimple designs. An Average shear Strength Of $35 \mathrm{Mpa}$ is noticed for joints. As a rule, the higher warmth info will prompt a genuine relaxing of $\mathrm{Al}$ sheet, which diminishes the mechanical exhibition at the welding.

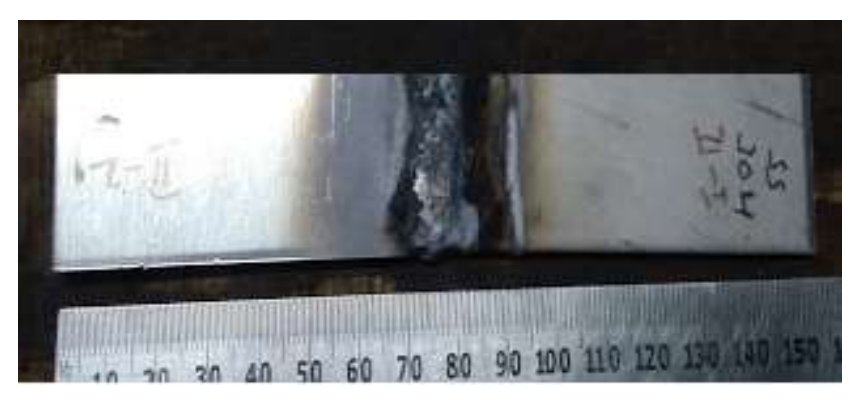

Fig 4: Specimen For Shear test

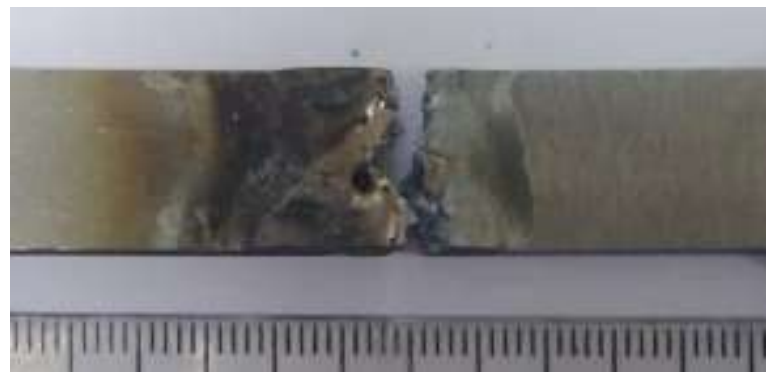

Fig 5: Specimen after Shear Test 


\section{Prediction and optimization by ANOVA}

The significance of the welding parameters and their performance can be determined by analysis of variance (ANOVA). By calculating sums of squares, means of squares, and the percentage contribution of each welding parameter, we arrive at our results. A separate analysis of parameters was done to predict and optimize the welding parameters. In which the maximum value is $132 \mathrm{MPa}$ is found at the weld current of $100 \mathrm{~A}$, weld speed of $90 \mathrm{~mm} / \mathrm{min}$, and the gas flow rate of $9 \mathrm{Lit} / \mathrm{min}$ shown in fig 7 . With the data an attempt was made to find the prediction of tensile strength by using the regression equation was made and the values were found. The values predicted was very close to the experimental values and are shown in Fig 6. At a current of $101.71 \mathrm{~A}$, at a speed of 90.90 and gas flow rate of 9.15 an optimum tensile strength of 132.85 $\mathrm{MPa}$ is predicted.

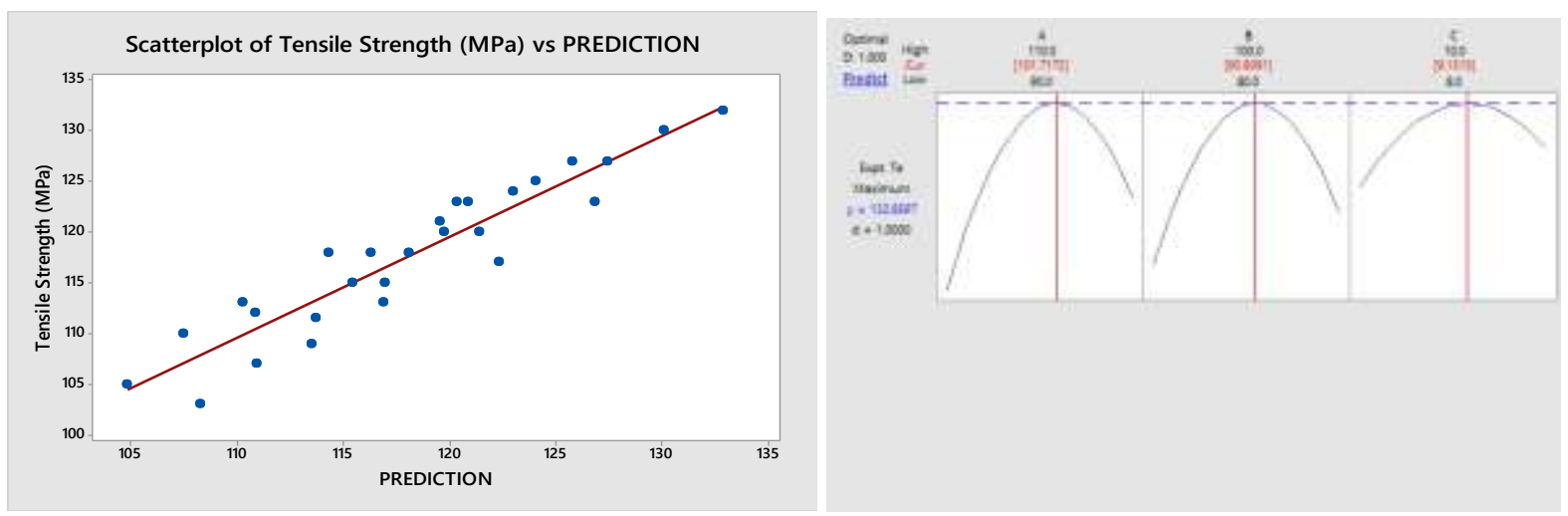

Fig 6: Expt Tensile Strength vs Predicted Strength

Fig 7: Optimum Parameters

\section{Microstuctures}

Scanning Electron Microscopic images reveal the formation of Intermetallic Compounds in aluminum-Steel welded butt joint[22-26]. In the welded wrinkle interface, a noticeable difference in thickness of the IMC layer has been observed, resulting in a variety of models grouped in one layer. IMC detected a spiked structure that is regular and oriented towards the weld interface, and its thickness is typically $5-7 \mathrm{~mm}$. A couple of examinations have shown that, to get productive weld joint by welding-brazing, an Intermetallic Compound layer is essential, even it may not make in excess of $10 \mathrm{~mm}$ on the weld area by then, it winds up being superfluously fragile for specific clarification. Because of the more significant warmth obligation to the upper part of the interface district, the interface at the upper portion of the interface district is thicker than that at the lower portion of the interface district (b). Copper, on the other hand, presents a very restricted development with its assistance formed development, and the thickness of the copper material is $2-3 \mathrm{~mm}$. 


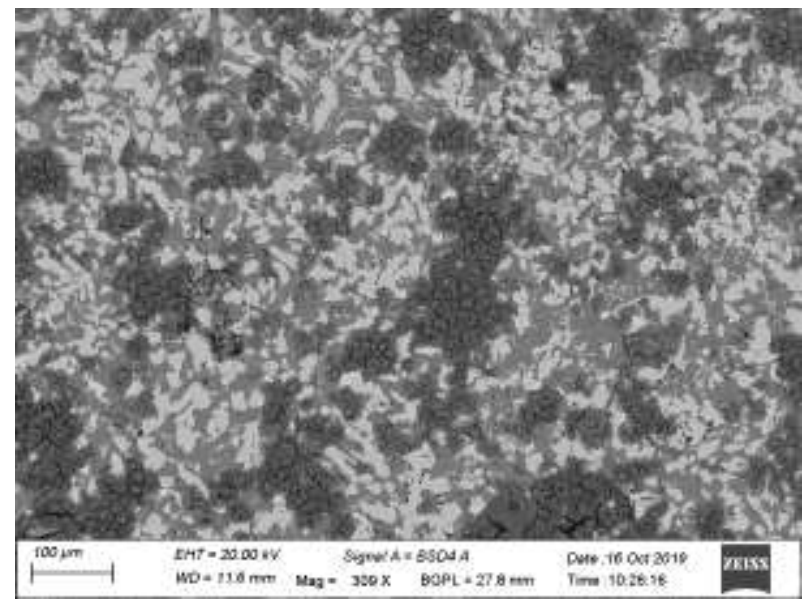

(a)

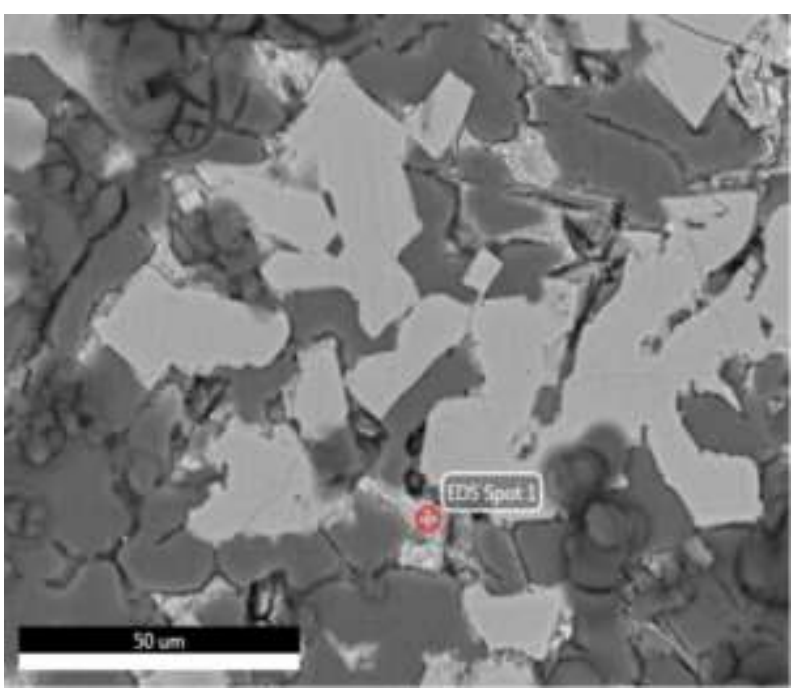

(c)

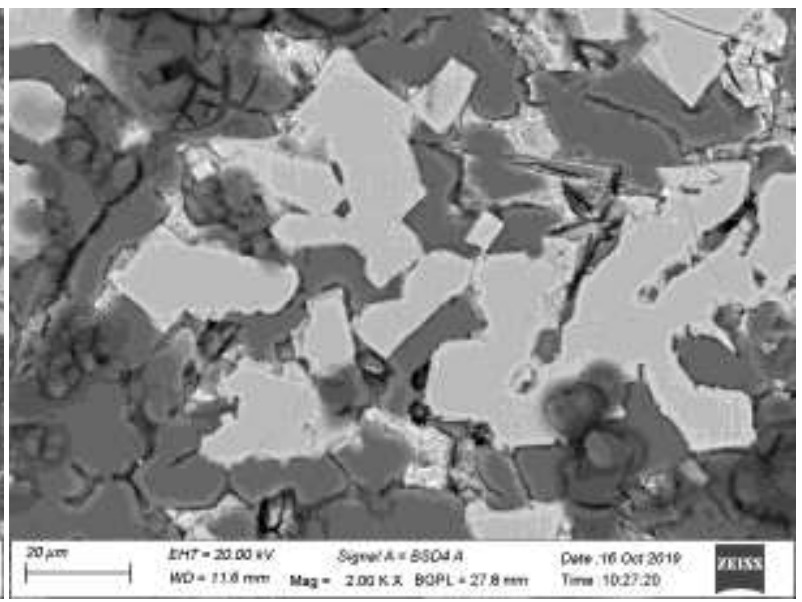

(b)

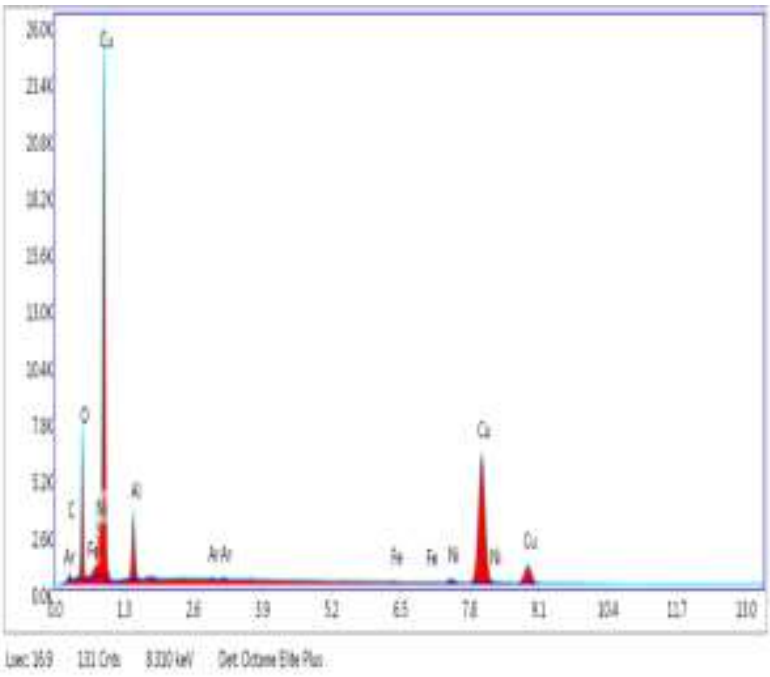

(d)

Fig 8: (a),(b)SEM and(c)(d) EDS Images

The presence of copper $(\mathrm{Cu})$ responds with Aluminum( $\mathrm{Al})$ molecules to epitomize $\mathrm{Al}-\mathrm{Cu}$ bonds in $\mathrm{Al}_{13}\left(\mathrm{Fe}_{\mathrm{m}} \mathrm{Cu}_{\mathrm{n}}\right)_{4}$. The $\mathrm{Al}-\mathrm{Cu}$ bond displays a solid bond so $\mathrm{Al}_{13}\left(\mathrm{Fe}_{\mathrm{m}} \mathrm{Cu}_{\mathrm{n}}\right)_{4}$. presents high break opposition. Then again, copper presence in filler may diminish the dispersibility and bifurcating paces of Iron( $\mathrm{Fe})$ in the aluminum liquid pool. It was discovered that use of motion is significant in aluminum brazing, transition can upgrade the solvency and wettability of aluminum in steel. Motions are hostile to destructive so a motion of $30 \%$ weight rate is utilized $\mathrm{A}$ stage change of $\mathrm{Al}_{6} \mathrm{fe}$ to $\mathrm{Al}_{x} \mathrm{Fe}_{\mathrm{y}} \mathrm{Cu}$ is noticed. The diminishing in IMC thickness will influence the strength of the joint. The more abatement prompts a more expansion in strength. An expansion in the quantity of Steel and Copper will prompt crack. Cu joins with Al liquefy and diffuses with weld pool. Copper will diminish the development of IMC by dissolving the components of steel. Amount of accelerate stages and diminishing in thickness has lead to an expansion in strength The IMC layers move from $(\alpha-\mathrm{Al}+\mathrm{FeAl} 3)$ in weld zone to $\left(\mathrm{Fe}_{2} \mathrm{Al}_{5}+\mathrm{FeAl}_{2}\right) \mathrm{I}$ focal point of the layer to $\left(\mathrm{FeAl}_{2}+\mathrm{FeAl}\right)$ in the steel side $\mathrm{CuAl}_{2}, \mathrm{Fe}_{2} \mathrm{Al}_{5}, \mathrm{Fe}_{4} \mathrm{Al}_{13}$. The Sem pictures of intermetallics and crack pictures are appeared in Fig 8 (a),(b) . 


\section{Conclusions}

Below observations were concluded from the results and discussions.

1. A effective TIG weld butt joint was framed between different AA6061 aluminum compounds and SS304 hardened steel amalgam with Copper Filler rod.

2. An average tensile strength of $117 \mathrm{Mpa}$ is accomplished.

3. The Validation of experimental tensile strength is tried with Anova, with three inputs(Current, weld speed, gas stream rate). The anticipated elasticity was contrasted and test esteems and the errors discovered was intently and discovered acceptable.

4. Weld boundaries like Current, Gas stream rate, and weld speed were upgraded with the assistance of Analysis of Variance. It was discovered that Welding current made sure about the main goal followed by Welding pace and Gas stream rate.

5. Presence of copper in filler responded with Aluminum atoms and formed Aluminum-Copper bonds in $\mathrm{Al}_{13}\left(\mathrm{Fe}_{\mathrm{m}} \mathrm{Cu}_{\mathrm{n}}\right)$ stage.

6.Al- $\mathrm{Cu}$ bond presents solid bond so $\mathrm{Al}_{13}\left(\mathrm{Fe}_{\mathrm{m}} \mathrm{Cu}_{\mathrm{n}}\right)$ displays high break obstruction.

\section{References}

[1] Qiu R, Satonaka S, Iwamoto C. Effect of interfacial reaction layer continuity on the tensile strength of resistance spot welded joints between aluminium alloy and steels. Materials and Design 2009 (9) 30:3686-3689.

[2] Staubach M, Juttner S, Fussel U, Dietrich M. Joining of steel-aluminium mixed joints with energyreduced GMA processes and filler materials on an aluminium and zinc basis. Welding Cutting 2008 (1) 7:30-38.

[3] Acarer M, Demir B. An investigation of mechanical and metallurgical properties of explosive welded aluminium-dual phase steel.Materials Letters 2008 (25) 62:4158-4160.

[4] Kimura M, Ishii H, Kusaka M, Kaizu K, Fuji A. Joining phenomena and joint strength of friction welded joint between pure aluminium and low carbon steel. Science and Technology of Welding Joining 2009 (5) 14:388-395.

[5] Nezhad M, Ardakani A. A study of joint quality of aluminium and low carbon steel strips by warm rolling.Materials and Design 2009 (4) 30:1103-1109.

[6] Achar DRG, Ruge J, Sundaresan S. Metallurgical and mechanical investigations of aluminium-steel fusion welds. Aluminium 1980 (6) 56:391-397.

[7] Lin S, Song J, Yang C, Ma G. Microstructure analysis of interfacial layer with tungsten inert gas welding-brazing joint of aluminium alloy/stainless steel. ActaMetallurgicaSinica 2009 (10) 45:12111216 . 
[8]Mathers, G. The Welding of Aluminium and Its Alloys; Woodhead: Cambridge, England, 2002; pp. 4$14,32,97$.

[9]. Zhang, W.; Sun, D.; Han, L.; Gao, W.; Qiu, X. Characterization of intermetallic compounds in dissimilar material resistance spot welded joint of high strength steel and aluminum alloy. ISIJ Int. 2011, $51,1870-1877$.

[10]. Qiu, R.; Iwamoto, C.; Satonaka, S. Interfacial microstructure and strength of steel/aluminum alloy joints welded by resistance spot welding with cover plate. J. Mater. Process. Technol. 2009, 209, 41864193.

[11]. Zaeh, M.F.; Moesl, J.; Musiol, J.; Oefele, F. Material processing with remote technologyRevolution or evolution? Phys. Procedia 2010, 5, 19-33. [CrossRef]

[12]. Fan, J.; Thomy, C.; Vollertsen, F. Effect of thermal cycle on the formation of intermetallic compounds in laser welding of aluminum-steel overlap joints. Phys. Procedia 2011, 12, 134-141.

[13]. Lim, Y.C.; Squires, L.; Pan, T.Y.; Miles, M.; Song, G.L.; Wang, Y.; Feng, Z. Study of mechanical joint strength of aluminum alloy 7075-T6 and dual phase steel 980 welded by friction bit joining and weld-bonding under corrosion medium. Mater. Des. 2015, 69, 37-43.

[14]. Honggang Dong, Wenjin Hu, YupingDuan, Xudong Wang, Chuang Dong. Dissimilar metal joining of aluminum alloy to galvanized steel with $\mathrm{Al}-\mathrm{Si}, \mathrm{Al}-\mathrm{Cu}, \mathrm{Al}-\mathrm{Si}-\mathrm{Cu}$ and $\mathrm{Zn}-\mathrm{Al}$ filler wires.Journal of Materials Processing Technology 2012 (212):458-464.

[15]. He, H., Lin, S., Yang, C. et al. Combination Effects of Nocolok Flux with Ni Powder on Properties and Microstructures of Aluminum-Stainless Steel TIG Welding-Brazing Joint. J. of Materi Eng and perform $2013,22,3315-3323$.

[16]. Song, J.L.; Lin, S.B.; Yang, C.L.; Ma, G.C.; Liu, H. Spreading behaviour and microstructure characteristics of dissimilar metals TIG welding-brazing of aluminium alloy to stainless steel. Materials Science and Engineering A 2009 (509):31-40.

[17]. Lin, S.B.; Song, J.L.; Yang, C.L.; Fan, C.L.; Zhang, D.W. Brazability of dissimilar metals TIG butt welding-brazing between aluminium alloy and stainless steel with $\mathrm{Al}-\mathrm{Cu}$ filler. Materials and Design 2010 (31):2637-2642.

[18]. Muralimohan Cheepu et al. Dissimilar Joining of Stainless Steel and 5083 Aluminum Alloy Sheets by Gas Tungsten Arc Welding-Brazing Process. IOP Conference Series: Materials Science and Engineering 2018 (330):012048.

[19] Mandal, N.R. Welding and Distortion Control; Narosa Publishing House: Kharagpur, India, 2004; pp. 95-98.

[20] Kou, S. Welding Metallurgy, 2nd ed.; John Wiley: Hoboken, NJ, 2003; 124 pp.

[21] Song, J.L.; Lin, S.B.; Yang, C.L.; Fan, C.L. Effects of Si addition on intermetallic compound layer of aluminium-steel TIG welding-brazing joint. Journal of Alloys and Compounds 2009 (488):217-222.

[22]. : S. Kotari, E. Punna, S. M. Gangadhar et al., Dissimilar metals TIG welding-brazing of AZ31 magnesium alloy to 304 stainless steel, Materials Today: Proceedings, matpr.2020.05.553

[23]. J. L. Song, S. B. Lin, C. L. Yang, C. L. Fan, G. C. Ma. Analysis of intermetallic layer in dissimilar TIGwelding-brazing butt joint of aluminium alloyto stainless steel.Science and Technology of Welding \& Joining 201015(3):213-218.

[24] S.B.LinJ.L.SongC.L.YangC.L.FanD.W.Zhang, Brazability of dissimilar metals tungsten inert gas butt welding-brazing between aluminum alloy and stainless steel with $\mathrm{Al}-\mathrm{Cu}$ filler metal, mater design ,2010,5, 2637-2642. 
[25]. A. BalaramNaik, A. Chennakeshava Reddy. Optimization of tensile strength in TIG welding using the Taguchi method and analysis of variance (ANOVA).Thermal Science and Engineering Progress 2018 (8):327-339.

[26] S. Kotari et al Mechanical and micro structural behaviour of flux coated GTAW andFSW joined AA6061 aluminium alloy. Materials Today: Proceedings 2020 (27) 1660-1667. 